\title{
GROWTH AND PROPERTIES OF W-B-N DIFFUSION BARRIERS DEPOSITED BY CHEMICAL VAPOR DEPOSITION
}

\author{
J.G. Fleming*, E. Roherty-Osmun, J. Custer, Paul Martin Smith, J. S. Reid** † \\ and M.-A. Nicolet** \\ *Sandia National Laboratories, Org. 1323, MS 1085, P.O. Box 5800 , \\ Albuquerque NM 87185. Phone (505) 844 9158, FAX (505) 8442991 \\ **California Institute of Technology, Pasadena, CA 91125. \\ $\dagger$ Current Address, Intel Corporation, Hillsboro, OR, 97124.
}

\begin{abstract}
We have used chemical vapor deposition to grow ternary tungsten-based diffusion barriers to determine if they exhibit properties similar to those of sputter-deposited ternaries. A range of different W-B-N compositions in a band of compositions roughly between 20 and $40 \% \mathrm{~W}$ were produced. The deposition temperature was low, $350^{\circ} \mathrm{C}$, and the precursors used are well accepted by the industry. Deposition rates are high for a diffusion barrier application. Resistivities range from 200 to $20000 \mu \Omega-\mathrm{cm}$, the films with the best barrier properties having $-1000 \mu \Omega-\mathrm{cm}$ resistivities. Adhesion to oxides is sufficient to allow these films to be used as the adhesion layer in a tungsten chemical mechanical polishing plug application. The films are $\mathrm{x}$-ray amorphous as-deposited and have crystallization temperatures of up to $900^{\circ} \mathrm{C}$. Barrier performance against $\mathrm{Cu}$ has been tested using diode test structures. A composition of W. ${ }_{23} \mathrm{~B} .49 \mathrm{~N} .28$ was able to prevent diode failure up to a $700^{\circ} \mathrm{C}, 30$ minute anneal. These materials, deposited by CVD, display properties similar to those deposited by physical deposition techniques.
\end{abstract}

\section{INTRODUCTION}

There is currently great interest in the chemical vapor deposition (CVD) of diffusion barriers for both aluminum based and future copper based metallization schemes. It has been demonstrated that ternary, refractory based thin films are excellent diffusion barriers to both copper and aluminum [1-6]. In particular the W-B-N system has been studied by Reid et al [7]. However, these materials have typically been deposited by physical deposition and it is not expected that this approach can be used to deposit films with adequate step coverage and barrier properties under the more aggressive aspect ratios and maximum film thicknesses currently envisioned for 0.18 micron geometries and beyond. Films deposited by chemical vapor deposition exhibit superior step coverage's compared with those realized by physical deposition techniques. However, the two deposition techniques are so dissimilar that it is unclear whether or not the excellent barrier characteristics of sputter based ternary refractory alloys will also be displayed films deposited by CVD. Due to the relatively more complex nature of the CVD process, it is also unclear that practically interesting compositions can be obtained using this technique. In the work described below, we have used CVD to grow ternary tungsten-based diffusion barriers to determine if they do, in fact, exhibit properties similar to those of sputter deposited ternaries. We have chosen the W-B-N system since all the components are well known to the semiconductor industry, accepted precursors exist for each component, and there is data indicating that sputtered W-B-N films display excellent barrier properties [7]

\section{EXPERIMENTAL}

Six inch wafers were used throughout this work. Depositions were conducted on either thermal oxide, plasma-enhanced CVD oxide or on diode, step coverage, or chemical mechanical polishing test structures. The deposition system was a simple, cold wall, load locked, single wafer reactor. The tungsten precursor was $\mathrm{WF}_{6}$, which was mixed with a 


\section{DISCLAIMER}

Portions of this document may be illegible in electronic image products. Images are produced from the best available original document. 


\section{DISCLAIMER}

This report was prepared as an account of work sponsored by an agency of the United States Government. Neither the United States Government nor any agency thereof, nor any of their employees, make any warranty, express or implied, or assumes any legal liability or responsibility for the accuracy, completeness, or usefuiness of any information, apparatus, product, or process disclosed, or represents that its use would not infringe privately owned rights. Reference herein to any specific commercial product, process, or service by trade name, trademark, manufacturer, or otherwise does not necessarily constitute or imply its. endorsement, recommendation, or favoring by the United States Government or any agency thereof. The views and opinions of authors expressed herein do not necessarily state or reflect those of the United States Government or any agency thereof. 
combination of $\mathrm{SiH}_{4}, \mathrm{NH}_{3}$, and $30 \% \mathrm{~B}_{2} \mathrm{H}_{6}$ in $\mathrm{N}_{2}$. Argon was used as a carrier gas. The Ar, $\mathrm{WF}_{6}$ and $\mathrm{SiH}_{4}$ flows were typically 200,5 , and $3 \mathrm{sccm}$ respectively. The $\mathrm{NH}_{3}$ and $\mathrm{B}_{2} \mathrm{H}_{6}$ flows were varied between 10 and $70 \mathrm{sccm}$. The gases were distributed through separate injection rings spaced 4 inches above the surface of the wafer and were allowed to mix only in the low pressure reaction chamber. The deposition pressure was typically 500 to $700 \mathrm{mT}$ orr. The system was pumped using an oil based mechanical pump. The wafer temperature was typically $350^{\circ} \mathrm{C}$. The composition of the films was determined by RBS, ERD and SIMS. Surface morphology and film thickness were determined by SEM. Sheet resistivites were determined with a four point probe. The junctions of the diode test structures were formed by implanting $8 \times 10^{15} \mathrm{As}^{+} \mathrm{cm}^{2}$ into a $30 \Omega \mathrm{cm}, 10 \mu \mathrm{m}$ p-type epitaxial layer. The junction depth and area are $280 \mathrm{~nm}$ and $250 \mu \mathrm{m} \times 250 \mu \mathrm{m}$. The chemical mechanical polishing test structure consisted of a series of via arrays of various sized holes on a variety of pitches patterned through PECVD oxide down to silicon. Following deposition of the thin film W-B-N diffusion barrier/adhesion layer, $8000 \AA$ of $C V D$ tungsten was deposited at $430^{\circ} \mathrm{C}$. The wafers were then chemically mechanically polished using a commercially available slurry and tool.

\section{RESULTS AND DISCUSSION}

Tungsten was incorporated into the films through the reduction of $W_{6}$. Thermodynamics predicts that silane is the preferred reductant in the gas mixture. The ratio of $\mathrm{WF}_{6}$ to $\mathrm{SiH}_{4}$ was greater than 1 , and $\mathrm{Si}$ incorporation was typically less than 5 atomic percent. Because $\mathrm{B}_{2} \mathrm{H}_{6}$ is unstable at room temperature, we believe that boron was incorporated into the films through simple decomposition of $\mathrm{B}_{2} \mathrm{H}_{6}$, possibly catalyzed by the presence of tungsten. Nitrogen was incorporated through the reaction of ammonia with tungsten on the hot wafer surface.

The deposition rates are high for a diffusion barrier application, ranging from 500 to $2000 \AA$ per minute. The rate increases with lower flows of ammonia and higher flows of diborane and silane. The films are featureless both visually and under SEM examination, even when one micron thick, Figure 1. The films were blue-gray to brown-gray in color.

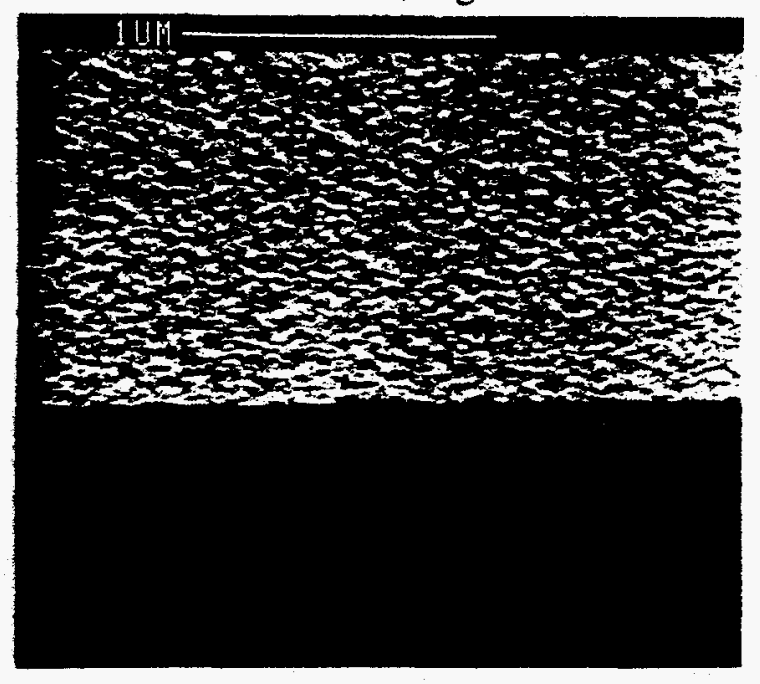

Figure 1.

Surface morphology of a typical film. Though thick, the film remains smooth without signs of crystallinity or porosity.

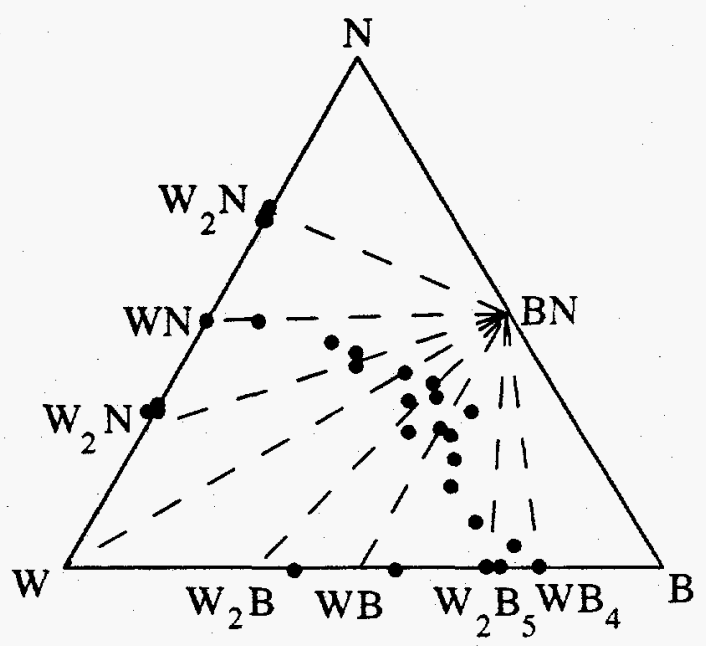

Figure 2.

Compositions grown and tentative system tie lines. We were able to grow compositions ranging from roughly $\mathrm{WB}_{4}$ to $\mathrm{W}_{2} \mathrm{~N}$. (After Reid et al [7])

The compositions grown are indicated on the W-B-N ternary phase diagram, Figure 2. Even though the temperature used was relatively low, there was little hydrogen incorporation in the film, typically $\sim 5 \%$ as determined by ERD. We were able to deposit ternary compositions lying in a band roughly between 20 and $40 \%$ tungsten. In general, increasing the partial pressure of either $\mathrm{B}_{2} \mathrm{H}_{6}$ or $\mathrm{NH}_{3}$ increased the fraction of the appropriate element in the 
film. Figure 3 demonstrates this in a plot of fraction $\mathrm{N}$ in the film as a function of $\mathrm{NH}_{3}$ partial pressure. Step coverage was $-30 \%$ on samples with aspect ratios of 4.5 and 1 micron diameter. However, the deposition conditions were not optimized for step coverage and we believe that the very high surface area $\left(-450 \mathrm{~cm}^{2}\right)$ of the test structure used may have degraded the step coverage.

We were unable to increase the tungsten fraction in the film by either increasing the $\mathrm{WF}_{6}$ partial pressure by a factor of eight or by varying the temperature from $\sim 200^{\circ} \mathrm{C}$ to $-400^{\circ} \mathrm{C}$. At the lowest temperature, the deposited films were unstable in air, possibly due to the presence of unreacted boron or boron hydrides. The exact reason for this restriction in the range of $\mathrm{W}$ fraction is unknown, though there is some evidence that it is related to the surface character of the growing film. Figure 4 shows the atomic percent of hydrogen in the growing film as a function of $\mathrm{WF}_{6}$ partial pressure. Films grown under conditions of higher $\mathrm{WF}_{6}$ partial pressure had no detectable levels of hydrogen and under these conditions we were unable to grow the ternary, growing instead either $W$ or the binaries. Since $H$ is found in the ternary films deposited under lower $W_{6}$ partial pressure conditions, we speculate that the surface of these growing layers is less densely fluorine terminated. However, as the $W_{6} F_{6}$ partial pressure is increased, we speculate that the surface becomes fully $F$ terminated. Change in surface termination have been observed in the $\mathrm{WF}_{6}-\mathrm{SiH}_{4}$ system [8]. We infer from this that growth of the ternary may be affected by the nature of the surface termination.

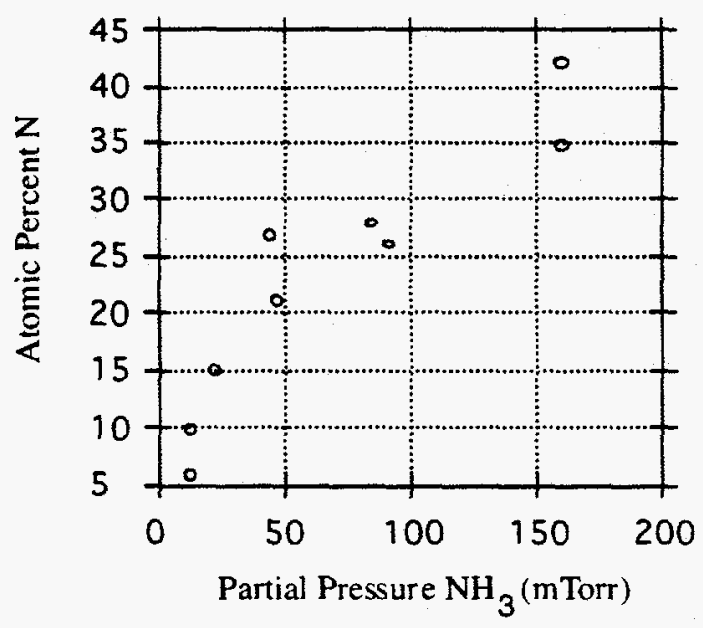

Figure 3.

Plot of fraction $\mathrm{N}$ in the film as a function of ammonia partial pressure.

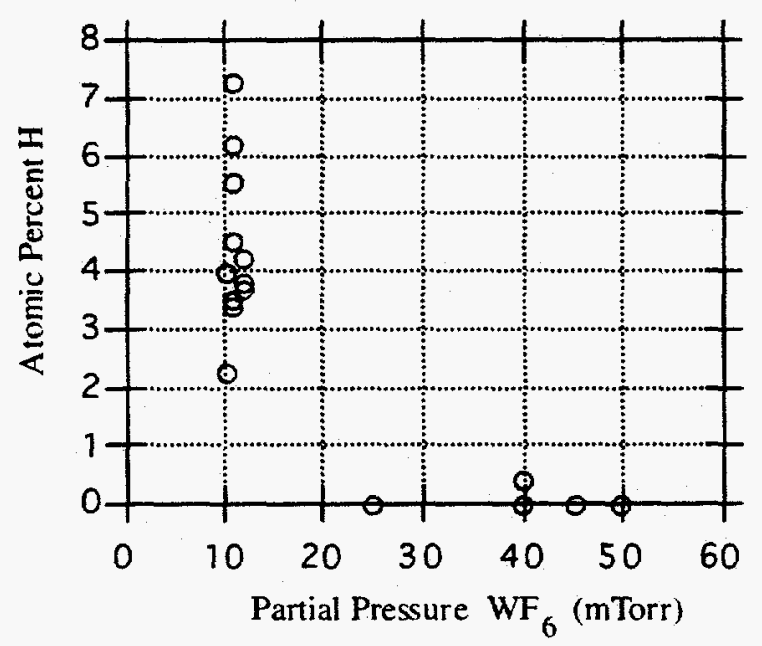

Figure 4.

Plot of $\% \mathrm{H}$ in the film as a function of $\mathrm{WF}_{6}$ partial pressure.

Both SIMS and RBS indicated that the films are uniform through their bulk. The asdeposited films are X-ray amorphous. However, we have been able to identify FTIR transmission peaks associated with $B-N$ bonding using FTIR on samples less than $500 \AA$ in thickness.

The as-deposited films have resistivities ranging from $200 \mu \Omega-\mathrm{cm}$ for $\mathrm{WB}_{\mathrm{X}}$ rich films, to $\sim 20000 \mu \Omega-\mathrm{cm}$ for $\mathrm{WN}_{\mathrm{X}}$ rich films. Films of intermediate composition with good barrier properties typically had resistivities of $\sim 1000 \mu \Omega-\mathrm{cm}$. In general, ternary films with a higher fraction of "WN ${ }_{\mathrm{X}}$ " displayed a higher resistivity. Resistivity is plotted as a function of fraction $\mathrm{N}$ in the film in Figure 5.

Adhesion of the films to thermal and PECVD oxides appears to be acceptable for most compositions, especially when compared to CVD tungsten films. Unlike Ti based materials, the tungsten is unable to reduce the silicon dioxide to improve film adhesion. Bonding in this case may be the result of either B-O or Si-N interactions. As a practical test of adhesion we deposited $\sim 1000 \AA$ thick intermediate ternary compositions on a test structure consisting of arrays of holes of varying diameter and pitch. This was immediately followed by the deposition 
of $8000 \AA$ hydrogen reduced $W$ grown a 3 Torr and $430^{\circ} \mathrm{C}$. The tungsten and adhesion layer was then chemically mechanically polished back to the oxide. The end result is shown in figure 6 . There was no plug loss, however there was some delamination observed in the $\sim 200 \mu$ wide streets between hole arrays. While adhesion appears to be acceptable for certain applications more work is needed in this area to understand and possibly improve adhesion.

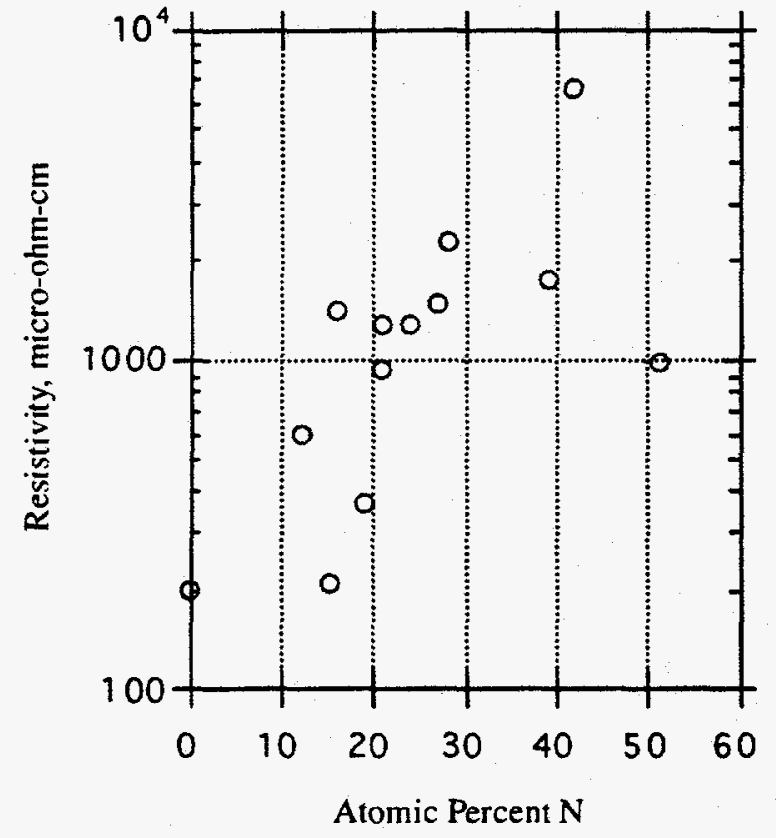

Figure 5.

Plot of resistivity as a function of $\mathrm{N}$ in the film.

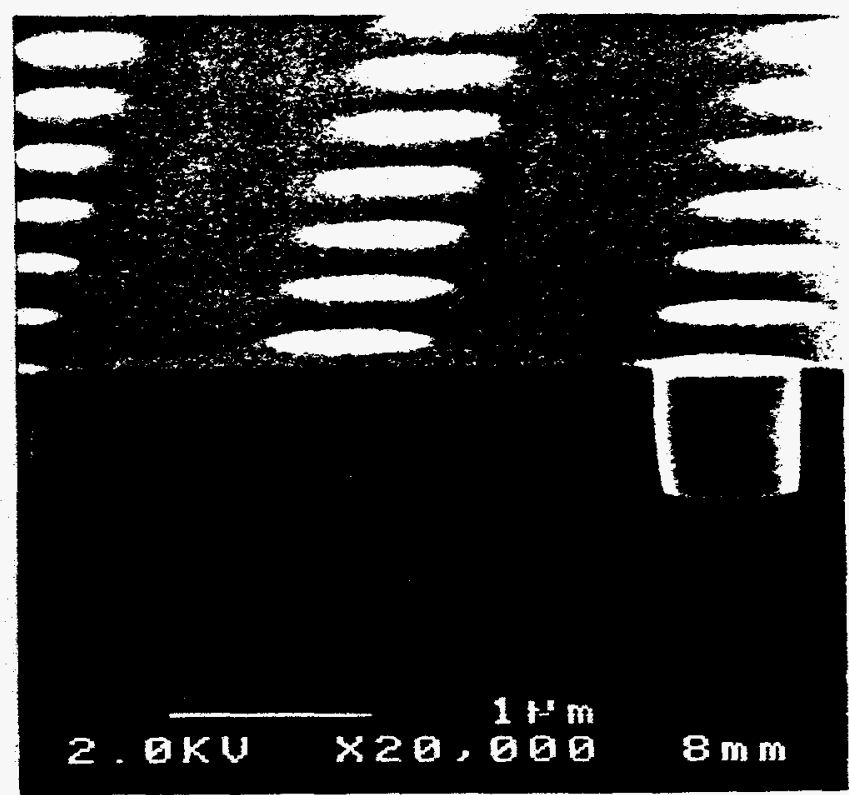

Figure 6.

Tungsten plugs formed by CMP using W. ${ }_{24}$ B. 39 N.37 as an adhesion-barrier layer.

If it is true that crystalline diffusion barriers fail by the diffusion of species along grain boundaries, then a rough measure of the effectiveness of these as deposited amorphous layers is their crystallization temperature. According to Read camera x-ray diffraction, the as deposited films are $x$-ray amorphous. Table 1 gives the crystallization temperatures of a range of compositions.

Table 1.

\section{Composition}

W.21B.63N. 16

W.26B.59N.15

W. $24 \mathrm{~B} .66 \mathrm{~N} .10$

W. 20 B .45 N. 35

W.24B.39N.37

W.29B.32N.39

W.24B.52N. 24

W.23B.49N.28
Diode Temp. (30 min. Vs. Cu)
$<600$
$<600$
$>600$
$>600$
$>600$
$>600$
$>600$
$\sim 700$

Crystallization Temp.

(1 hour anneal)

$$
\begin{aligned}
& <700 \\
& >700 \\
& >700 \\
& <900
\end{aligned}
$$

Certain film compositions remain partially amorphous even after a 1 hour anneal at $900^{\circ} \mathrm{C}$. This compares very well with ternary diffusion barriers deposited by PVD techniques and is the first indication that these CVD deposited films may have properties similar to ternary PVD materials. 
To test these materials resistance to $\mathrm{Cu}$ diffusion, diode test structures were used. The thickness of the barrier was $1000 \AA$ and the samples were held at temperature for 30 minutes. The results are summarized in Table 1. After anneal, the reverse leakage was measured on eight diodes per composition. The best result obtained was the prevention of diffusion up to $700^{\circ} \mathrm{C}$. Films with good barrier properties had compositions slightly more boron rich than the intersection of the W-BN tie line to the band of ternary compositions able to be accessed. The resistivities of these films are roughly $1000 \mu \Omega-\mathrm{cm}$. While this diffusion barrier performance is not as good as the results obtained with certain of the ternary PVD films, it is very respectable and more than adequate in terms of the thermal budget envisioned for advance $\mathrm{Cu}$ and $\mathrm{Al}$ metallization processes.

\section{CONCLUSION}

A range of different $\mathrm{W}-\mathrm{B}-\mathrm{N}$ compositions in a band of compositions roughly between 20 and $40 \% \mathrm{~W}$ have been produced using CVD. The deposition temperature was low, the precursors used are well accepted by the industry and the deposition rates are high for a diffusion barrier application. Film resistivities range from 200 to $20000 \mu \Omega-\mathrm{cm}$, the films with the best barrier properties having $-1000 \mu \Omega-\mathrm{cm}$ resistivities. More work is needed to understand and improve adhesion of these films to oxide, however, compositions displaying good barrier properties have been shown to be adequate for W via CVD and CMP applications. Preliminary results indicate that these materials, deposited by CVD, have barrier properties similar to those deposited by physical deposition techniques. The barrier characteristics observed using diode test structures are more than adequate for future advanced $\mathrm{Al}$ or $\mathrm{Cu}$ applications.

\section{ACKNOWLEDGMENTS}

The authors gratefully acknowledge the assistance of D. Hetherington for the CMP processing. This work was supported by the United States Department of Energy under Contract DE-AC04-94AL85000. J.S. Reid gratefully acknowledges a fellowship fron the Intel Foundation.

\section{REFERENCES}

1. E. Kolawa, P.J. Pokela, J.S. Reid, J.S. Chen, R.P. Ruiz and M.-A. Nicolet, IEEE Electron Device Leters 12, 321 (1991).

2. J.S. Reid, E. Kolawa and M.-A. Nicolet, J. Mater. Res. 7, 2424 (1992).

3. E. Kolawa, X. Sun, J.S. Reid, J.S. Chen and M.-A. Nicolet, Thin Solid Films 236, 301 (1993).

4. J.S. Reid, E. Kolawa, R.P. Ruiz and M.-A. Nicolet, Thin Solid Films 236, 319 (1993).

5. K.-C. Lin, E.Y. Chang, S.-P. Wang, Y.-L. Lai and C.-Y. Chang, Jpn, J. Appl. Phys. 33, 4547 (1994).

6. M. Eizenberg, K. Littau, S. Ghanayem, A. Mak, Y. Maeda, M. Chang and A.K. Sinha, Appl. Phys. Lett. 65, 2426 (1994).

7. J.S. Reid, R.Y. Liu, P.M. Smith, R.P. Ruiz and M.-A. Nicolet, Thin Solid Films 262, 218 (1995).

8. M.L. Yu, B.N. Eldridge and R.V. Joshi in Tungsten and Other Refractory Metals for VLSI Applications I, edited by R.S. Blewer and C.M. Mc Conica (MRS Pittsburgh. PA 1989), p.221. 